\title{
Microchip Flow Cytometer with Integrated Polymer Optical Elements for Measurement of Scattered Light
}

Wang, Zhenyu; El-Ali, Jamil; Perch-Nielsen, Ivan Ryberg; Mogensen, Klaus Bo; Snakenborg, Detlef; Kutter, Jörg Peter; Wolff, Anders

Published in:

International Conference on Micro Electro Mechanical Systems

Link to article, DOI:

10.1109/MEMS.2004.1290598

Publication date:

2004

Document Version

Publisher's PDF, also known as Version of record

Link back to DTU Orbit

Citation $(A P A)$ :

Wang, Z., El-Ali, J., Perch-Nielsen, I. R., Mogensen, K. B., Snakenborg, D., Kutter, J. P., \& Wolff, A. (2004). Microchip Flow Cytometer with Integrated Polymer Optical Elements for Measurement of Scattered Light. International Conference on Micro Electro Mechanical Systems, 367-370.

https://doi.org/10.1109/MEMS.2004.1290598

\section{General rights}

Copyright and moral rights for the publications made accessible in the public portal are retained by the authors and/or other copyright owners and it is a condition of accessing publications that users recognise and abide by the legal requirements associated with these rights.

- Users may download and print one copy of any publication from the public portal for the purpose of private study or research.

- You may not further distribute the material or use it for any profit-making activity or commercial gain

- You may freely distribute the URL identifying the publication in the public portal 


\title{
Microchip Flow Cytometer with Integrated Polymer Optical Elements for Measurement of Scattered Light
}

\author{
Z. Wang, J. El-Ali, I.R. Perch-Nielsen, K.B. Mogensen, D. Snakenborg, J.P. Kutter and A. Wolff \\ MIC, Technical University of Denmark, Denmark
}

\begin{abstract}
:
Flow cytometry is a very powerful method for biophysical measurement of microparticles, such as cells and bacteria. In this paper, we report an innovative microsystem, in which several different optical elements (waveguides, lenses and fiber-to-waveguide couplers) are integrated with microfluidic channels to form a complete microchip flow cytometer. All the optical elements, the microfluidic system, and the fiber-to-waveguide couplers were defined in one layer of polymer (SU-8, negative photoresist) by standard photolithography. With only one single mask procedure, all the fabrication and packaging processes can be finished in one day. Polystyrene beads were measured in the microchip flow cytometer, and three signals (Forward Scattering, Large angle Scattering and Extinction) were measured simultaneously for each bead. The average intensities of the Forward Scattered light and the incident light Extinction showed excellent linear relationship with the sizes of the beads. To our knowledge this is the first time Forward Scattered light and incident light Extinction were measured in a microsystem using integrated optics. The microsystem can be applied for analyzing different kinds of particles and cells, and can easily be integrated with other microfluidic components
\end{abstract}

\section{Introduction}

Flow cytometry is widely used for analyzing chemicals, particles and cells in clinical diagnostics, biochemistry and biology. In flow cytometry cells flow through an incident light beam in a sensing region and parameters such as scattered light and fluorescence are measured to provide information on the cells (Figure 1) ${ }^{[1]}$.

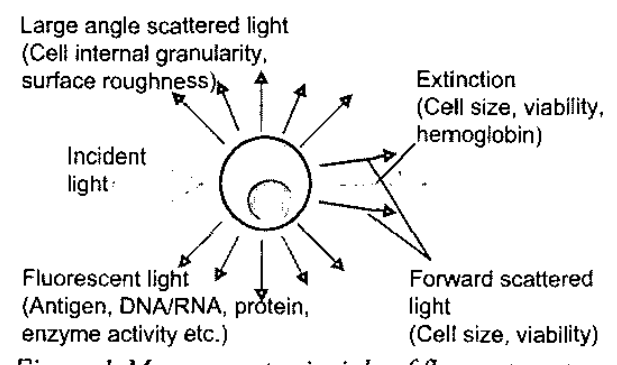

Figure 1:Measurment principle of flow cytometry.

Forward Scattering (FS) also called small angle scattering is measured in a very narrow scattering angle range $(0.5$ - $5.0^{\circ}$ to the incident light) and requires therefore very precise alignment. Consequently, FS is more difficult to measure than Large angle Scattering (LS), Extinction and Fluorescence ${ }^{[1,2]}$.

Flow cytometry can be combined with cell sorting in socalled fluorescent activated cell sorters (FACS ${ }^{[3]}$. FACS can provide impressive efficient sorting at rates of up to 1$2 \cdot 10^{3}$ cells/seconds, but FACS are expensive, complex and require specially trained personnel for operation and maintenance.

In the past two decades, the microfabrication technologies developed for the microelectronic industry have been applied for miniaturization of various (bio)chemical analytical instruments. Those technologies have also been utilized for miniaturizing flow cytometers ${ }^{[4-6]}$ and fluorescent activated cell sorters $(\mu \mathrm{FACS})^{[7,8]}$. However, nearly all biochemical microdevices using optical detection still rely on bulk optics. This is a drawback in terms of packaging because of alignment problems and shock stability. Furthermore, free-space optical elements are often difficult to miniaturize.

Integrating planar optical waveguides with the microfluidic channels may provide good solutions to these problems. Microfluidic devices with integrated silicon nitride or doped silicon dioxide waveguides have been presented in recent years ${ }^{[9 \sim 11]}$. They were fabricated using silicon micromachining techniques such as thin-film deposition and anisotropic etching with the use of two to four photolithographic mask steps. The fabrication procedures were relatively complicated and took at least a couple of weeks.

Polymers are potentially interesting materials for microfabricated devices because they are less expensive and less fragile than glass and silicon and easier to fabricate. Our lab has presented a biochemical microdevice in which the fluidic system, polymer optical waveguides, and couplers to external optical fibers are fabricated in one processing step ${ }^{[12]}$. Here we present a novel microchip flow cytometer with integrated polymer optical elements (waveguides and lenses) suitable for high performance measurement of scattered light. Both fabrication and packaging are simple and fast, resulting in devices that can be made and tested in one day. 


\section{Design and fabrication:}

The design of the microchip flow cytometer is illustrated in the upper part of Figure 2. All the channels and optical systems were defined by standard lithography in a single layer of SU-8 (XP2075 Microchem, refractive index $n=$ 1.59 at $635 \mathrm{~nm}$ ) negative photoresist. The SU-8 layer was spun on a $500 \mu \mathrm{m}$ Borofloat glass substrate $(\mathrm{n}=1.46)$ that served as waveguide buffer layer (Figure 2 top). Air acts as cladding on each side of the $30 \mu \mathrm{m}$ wide waveguides. Finally, a PDMS lid $(n=1.4)$ was utilized to seal the flow channels and to serve as top cladding layer (Figure 2 bottom). The thickness of the SU-8 layer (about $90 \mu \mathrm{m}$ ) was adjusted to readily accommodate $70 \mu \mathrm{m}$ outer diameter optical fibers in the fiber couplers. The tapered groove of the coupler structure ensured self-alignment and thus very efficient coupling of light between fiber and planar waveguide. The width of the microfluidic channel was $600 \mu \mathrm{m}$ and the total dimensions of the chip were $16 \mathrm{~mm} \times 14 \mathrm{~mm}$.
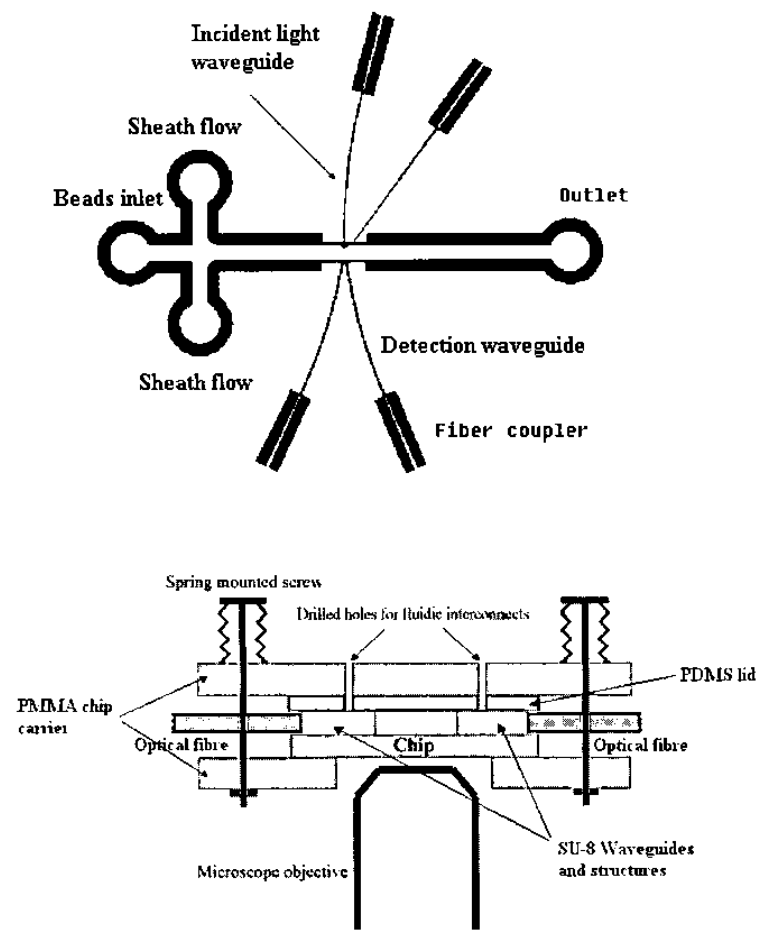

Figure 2: Schematic of the microchip flow cytometer's structure and packaging. Top: Design of the microchip flow cytometer. Bottom: Schematic of the chip's packaging.

The microchip flow cytometer has one sample inlet (beads inlet) and two sheath flow inlets. The sample flow is hydrodynamically focused in the center of the channel by the two sheath flows. In the center part of the chip, several optical elements were integrated with the microfluidic channel to measure scattered light from particles. A photo image of these essential integrated optical elements (lens, tapers and waveguides) in the center area of the flow cytometer is shown in Figure 3 (top part). The incident beam's light path was visualized by filling the channel with a fluorochrome (Bodipy 650/665-X, excitation at $646 \mathrm{~nm}$, emission at $665 \mathrm{~nm}$ ) (Figure 3 bottom). This clearly illustrated that the lens focused the incident light beam near the center of the channel.
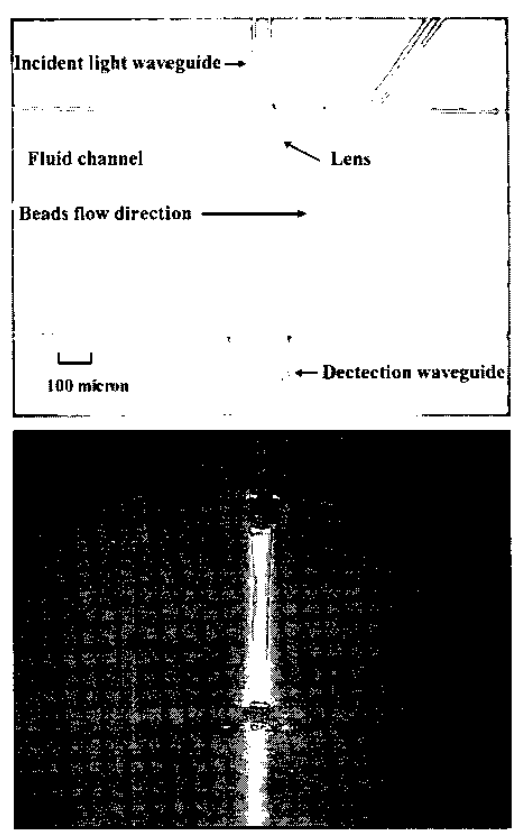

Figure 3: Top: Image of the essential integrated optical elements in the central part of the chip; Bottom: Light path visualized by filling the channel with a fluorochrome.

\section{Experimental Section:}

Four different sizes of polystyrene beads $(3,4.5,6$, and $9 \mu \mathrm{m}$ diameter) were percolated through the chip at a flow rate of $0.1-1.0 \mathrm{ml} / \mathrm{h}$. The beads were hydrodynamically focused in the channel by a flow of $2 \mathrm{ml} / \mathrm{h}$ MilliQ water through each of the two sheath flow channels (Figure 2). Incident light from a $\mathrm{HeNe}$ laser $(633 \mathrm{~nm})$ was introduced through an external optical fiber and the incident light waveguide and focused on the center of the channel by the integrated SU-8 lens (Figure 3). FS $\left(<5^{\circ}\right)$ was measured through the detection waveguide. However, this waveguide also received a small amount of direct incident light. Consequently, as a bead passes through the light beam a positive FS peak is observed first, followed by a negative Extinction (EX) peak as a result of the bead blocking the incident light (Figure 4).

LS $\left(90^{\circ}\right)$ was measured vertically through the microscope objective. Thus, for each bead 3 kinds of signals (FS, LS, EX) were measured simultaneously. 


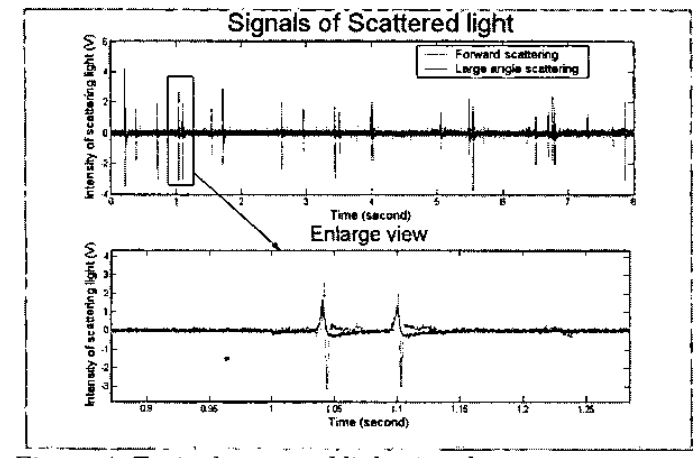

Figure 4: Typical scattered light signal traces.

\section{Results and Discussion:}

The scattering signals from the measured beads were plotted in histograms of the signal intensities (peak height). The histograms of Forward Scattered light intensities are shown in Figure 5 for the four different beads sizes.

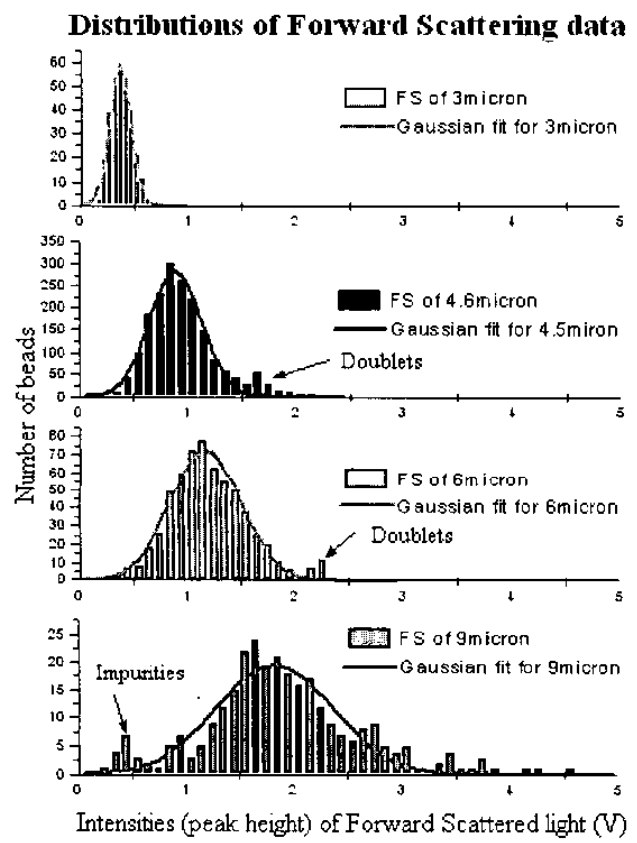

Figure 5: Distribution of Forward Scattered light intensities for different bead sizes.

In flow cytometry the coefficient of variation (CV) is defined as the standard deviation divided by the mean of the signal intensity. From the histograms, the $\mathrm{CV}$ can be calculated to be $26.6 \%, 27.4 \%, 28.2 \%$ and $29.7 \%$ for $3,4.5$, 6 and $9 \mu \mathrm{m}$ beads, respectively.

These results are comparable to other microchip flow cytometers $^{[4-6]}$. However, the $\mathrm{CV}$ in the microchip is high in comparison to conventional flow cytometry. This might be caused by several reasons: First, the ratio of sheath flow to sample flow is much higher in a conventional flow cytometer. Second, in the microchip flow cytometer the sample flow was only sheathed on the two lateral sides but not from the top and the bottom. This may give a greater variation in comparison to conventional flow cytometry, where the sample is sheathed and hydrodynamically focused from all four sides ${ }^{[8]}$. Third, in the chip flow cytometer we used syringe pumps, which give a slightly pulsing flow especially at low flow rates. In conventional flow cytometers the sheath flow is driven by air pressure to create very stable, pulse-free flow. In future work we will modify the design and operation of the microchip flow cytometer to bring the $\mathrm{CV}$ down to the level of conventional flow cytometers.

In the histograms for 4.5 and $6 \mu \mathrm{m}$ beads an additional small peak is seen at twice the average intensity. Incidences where two beads passing through the detection area simultaneously (doublets) cause this additional peak. In the histogram for $9 \mu \mathrm{m}$ beads an extra peak is seen in the low intensity area. This is due to an impurity of smaller particles in the beads sample.

During the measurements the throughput of beads was 425 beads $/ \mathrm{s}(4-25 \mathrm{~Hz})$. The widths of the signal peaks from the beads were around $10 \mathrm{~ms}$. The minimum distance between beads should be at least twice the signal peak width. This would limit the maximum theoretical throughput to $50-65 \mathrm{~Hz}$. However, increasing the flow rates will increase the linear velocity of the beads and thereby decrease the peak width and increase the theoretical throughput. Another possibility to increase the throughput is to decrease the width of the detection window or to narrow the incident light path.

Based on the distribution of the measured signal peak heights, the means of the FS, LS, and EX values were extracted after fitting to a Gaussian distribution (Figure 5 only shows the fits for FS). Mean peak heights were then plotted as a function of bead size and fitted by linear regression (Figure 6).

The results of the linear regressions show that FS and EX have a very strong linear dependence on the particle size (regression coefficients $\mathrm{r}=0.994$ and 0.991 , respectively), whereas LS has slightly less linear dependence $(r=0.979)$. This is in agreement with the literature which states that FS and EX provide information on particle size, whereas LS provides information on surface roughness and internal structure of the particles ${ }^{[1,2]}$. Here, LS only gave some information about the beads surface roughness, since all the polystyrene beads were solid. In the future, the microchip flow cytometer will be used to measure cells. These experiments will also include fluorescence labeling (FL) of cells to provide additional information on the cells. Then four different parameters (EX, FS, LS, and FL) can 
be measured simultaneously for each cell in the microchip flow cytometer.

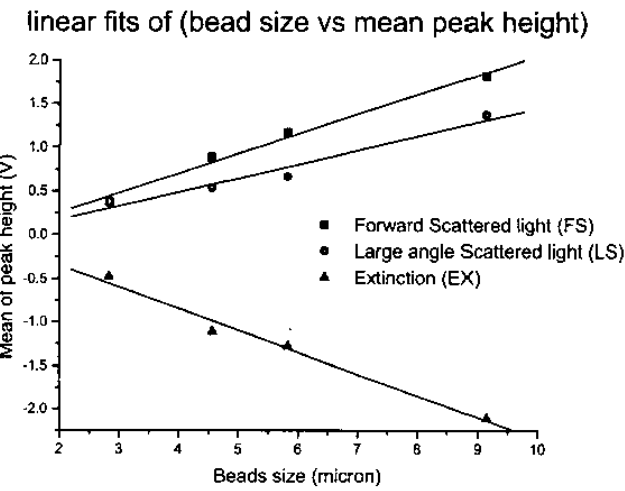

Figure 6: Linear fits of (bead size vs. mean peak height). Linear Regression for FS:

$Y=-0.19356+0.22449 * X$

$R=0.99403, S D=0.08046$

Linear Regression for $L S$ :

$Y=-0.14844+0.15912 * X$

$R=0.97882, S D=0.10871$

Linear Regression for $E X$ :

$Y=0.1608-0.25121^{*} X$

$R=-0.99118, S D=0.10972$

\section{Conclusion:}

To our knowledge this is the first time Forward Scattered light and incident light Extinction were measured in a microsystem using integrated optical elements. Polymer optical elements including waveguides, lenses and fiberto-waveguide couplers were integrated with microfluidic channels to form a microchip flow cytometer. The microfluidic system and all the optical elements were defined in one polymer layer (SU-8) by standard photolithography in one single mask step. This approach allows the rapid fabrication and packaging of the microchip flow cytometer with integrated polymer optical elements to be completed in a single day. Four different size polystyrene beads were tested in this micro device, and three different signals (Forward Scattering, Large angle Scattering and Extinction) were measured simultaneously for each bead. The different bead sizes could be distinguished from their signal intensities' distribution histograms. The relationships between the means of the signal peak heights and the size of beads also confirmed the viewpoints expressed in the literature, ${ }^{[1,2]}$ namely that Forward Scattered light $(R=0.994)$ and Extinction $(\mathrm{R}=0.991)$ provide information on beads size, and Large angle Scattered light $(\mathrm{R}=0.979)$ reveals information on the surface roughness of the beads. This microsystem can be applied for analyzing different kinds of cells or particles, and can easily be integrated with other microfluidic components.
Corresponding author: A. Wolff, MIC, Technical University of Denmark, Building 345e, $2800 \mathrm{Kgs}$. Lyngby, Denmark; Tel: +45 4525 6305; Fax: +454588 7762; Email: aw@mic.dtu.dk

\section{References:}

[1] Shapiro, H.M. Practical Flow Cytometry, 3rd edition, Willy-Liss, New York, 1995.

[2] E. Altendorf, D. Zebert, M. Holl and P. Yager, "Differential blood cell counts obtained using a microchannel based flow cytometer", Tranducers 97, IEEE, pp. 531-534, 1997.

[3] A. Orfao, and A. Ruiz-Arguelles, "General concepts about cell sorting techniques", Clinical Biochemistry, vol. 29(1), pp. 5-9, 1996.

[4] D.P. Schrum, C.T. Culbertson, S.C. Jacobson, and J.M. Ramsey, "Microchip flow cytometry using electrokinetic focusing", Analytical Chemistry, vol. 71(19), pp. 4173-4177, 1999.

[5] M.A. McClain, C.T. Culbertson, S.C. Jacobson, and J.M. Ramsey, "Flow cytometry of Escherichia coli on microfluidic devices", Analytical Chemistry, vol. 73(21), pp. 5334-5338, 2001.

[6] T. Buranda, J. Huang, V.H. Perez-Luna, B. Schreyer, L.A. Sklar, and G.P. Lopez, "Biomolecular recognition on well-characterized beads packed in microfluidic channels", Analytical Chemistry, vol. 74(5), pp. 1149-1156, 2002.

[7] A.Y. Fu, H.P. Chou, C. Spence, F.H. Amold, and S.R. Quake, "An integrated microfabricated cell sorter", Analytical Chemistry, vol. 74(11), pp. 2451-2457, 2002.

[8] A. Wolff, I.R. Perch-Nielsen, U.D. Larsen, P. Friis, G. Goranovic, C.R. Poulsen, J.P. Kutter, and P. Telleman, "Integrating advanced functionality in a microfabricated high-throughput flurescent-activated cell sorter", Lab on a Chip, vol. 3, pp. 22-27, 2003.

[9] O. Leistiko, and P. Friis, "Integrated bio/chemical Microsystems employing optical detection: the clipon", Journal of Micromechanics and Microengineering, vol. 6, pp. 148-150, 1998.

[10]P. Friis, K. Hoppe, O. Leistiko, K.B. Mogensen, J. Hübner, and J.P. Kutter, "Monolithic integration of microfluidic channels and optical waveguides in silica on silicon", Applied Optics, vol. 40(34), pp. 6246$6251,2001$.

[11] K.B. Mogensen, N.J. Petersen, J. Hübner, and J.P. Kutter, "Monolithic integration of optical waveguides for absorbance detection in microfabricated electrophoresis devices", Electrophoresis, vol. 22, pp. 3930-3938, 2001.

[12] K.B. Mogensen, J. El-Ali, A. Wolff, and J.P. Kutter, "Integration of polymer waveguides for optical detection in microfabricated chemical analysis systems", Applied Optics, vol. 42(19), pp. 4072-4079, 2003. 